\title{
Challenges in the Management of Hydrocephalic Children in Northern Mozambique
}

\author{
Sérgio Salvador ${ }^{1,3-5}$, João Carlos Henriques ${ }^{1,2}$, Missael Munguambe ${ }^{1}$, Rui M. C. Vaz ${ }^{3-5}$, Henrique P. Barros ${ }^{6,7}$
}

BACKGROUND: Hydrocephalus in sub-Saharan Africa, including Mozambique, is still a significant health care problem.

METHODS: Retrospective data from a previous study were used to determine patient provenance, referral patterns, and lost to follow-up rates.

RESULTS: Many children with hydrocephalus in this region are not taken to health care facilities for treatment. Reasons include poverty, difficult access, lack of transportation, and erroneous cultural interpretations. Resource limitations in terms of poorly equipped health care facilities and a lack of trained health professionals also contribute.

CONCLUSIONS: Efforts to improve prevention, early diagnosis, treatment, and follow-up are of utmost importance in Mozambique.

\section{INTRODUCTION}

$\mathrm{H}$ ydrocephalus is a medical condition resulting from a change in the dynamics of cerebrospinal fluid flow, with or without underlying pathology (20). If untreated, it can lead to significant impairment and even death (5). However, timely treatment can reduce morbidity and mortality as well as reduce the socioeconomic impact on families and communities $(\mathrm{I}, 28,30)$. Hydrocephalus is one of the most common developmental disorders, it is more common than Down syndrome and congenital deafness (8), and it is the most frequently treated neurosurgical condition in pediatric practice (IO, I2, 34).
Hydrocephalus is reported to be more common in developing countries; however, the prevalence (Io, 34) and incidence of hydrocephalus in sub-Saharan Africa are unknown (35). In this region, it is estimated that $<\mathrm{I} 0 \%$ of cases are treated using ventriculoperitoneal shunt (VPS) systems, meaning that most children who have this medical condition do not have access to needed treatment (23).

The population of Mozambique was approximately 24 million people in 2014 (I7); using data from developed countries to estimate incidence (35), we estimate there are 480 cases of congenital hydrocephalus and up to 4800 cases of neonatal hydrocephalus each year in Mozambique. Mozambique is divided into ro provinces and I capital city with provincial status. The provinces are subdivided into 129 districts. The districts are further divided in 405 administrative posts and then into localities, the lowest geographical level of the central state administration (Figure 1).

There is at least I health center in each district, but not all health centers have a physician. A patient with hydrocephalus from a locality would present to a health center (in the district capital) and would need referrals to a provincial hospital (tertiary level) and after that to I of the 3 quaternary central hospitals (in Maputo, Beira, and Nampula) to receive neurosurgical care. In parts of northern Mozambique, some patients are more than Iooo $\mathrm{km}$ from a health facility with a neurosurgeon (Figure 2). Mozambique has only 2 active national neurosurgeons in the public sector (Maputo and Nampula), and there are I4 foreign neurosurgeons working in the country (4 Cuban, 2 Russian, and 8 Korean).

In northern Mozambique, prenatal care is performed by health personnel (physicians, nurses, midwives, or auxiliary or traditional birth attendants) and reaches $90 \%-96 \%$ of pregnant women. However, assisted deliveries and postdelivery/neonatal care by skilled health personnel remain low throughout the country (54\%), ranging from $35.6 \%$ in Cabo Delgado province to $60.3 \%$ in

\section{Key words \\ - Hydrocephalus \\ - Infant \\ - Management \\ - Mozambique}

\section{Abbreviations and Acronyms}

VPS: Ventriculoperitoneal shunt

From the ${ }^{1}$ Department of Neurology and Neurosurgery of Faculty of Health Sciences, University of Lúrio, Nampula, Mozambique; ${ }^{2}$ Department of Neurosurgery, Central Hospital of Nampula, Nampula, Mozambique; ${ }^{3}$ Department of Neurosurgery, Centro Hospitalar São João, Oporto, Portugal; ${ }^{4}$ Department of Clinical Neurosciences and
Mental Health, Faculty of Medicine, University of Porto, Oporto, Portugal;

${ }^{5}$ Neurosciences Unit of CUF Porto Hospital, Oporto, Portugal; ${ }^{6}$ Institute of Public Health

of University of Porto, Oporto, Portugal; and ${ }^{\mathbf{7} D e p a r t m e n t ~ o f ~ C l i n i c a l ~ E p i d e m i o l o g y, ~}$

Predictive Medicine and Public Health of Faculty of Medicine, University of Porto,

Oporto, Portugal

To whom correspondence should be addressed: Sérgio Salvador, M.D.

[E-mail: sfsalvador.neurocirurgia@gmail.com]

Citation: World Neurosurg. (2015) 84, 3:671-676.

http://dx.doi.org/10.1016/j.wneu.2015.03.064

Journal homepage: www.WORLDNEUROSURGERY.org

Available online: www.sciencedirect.com

1878-8750/\$ - see front matter ๔ 2015 Elsevier Inc. All rights reserved. 


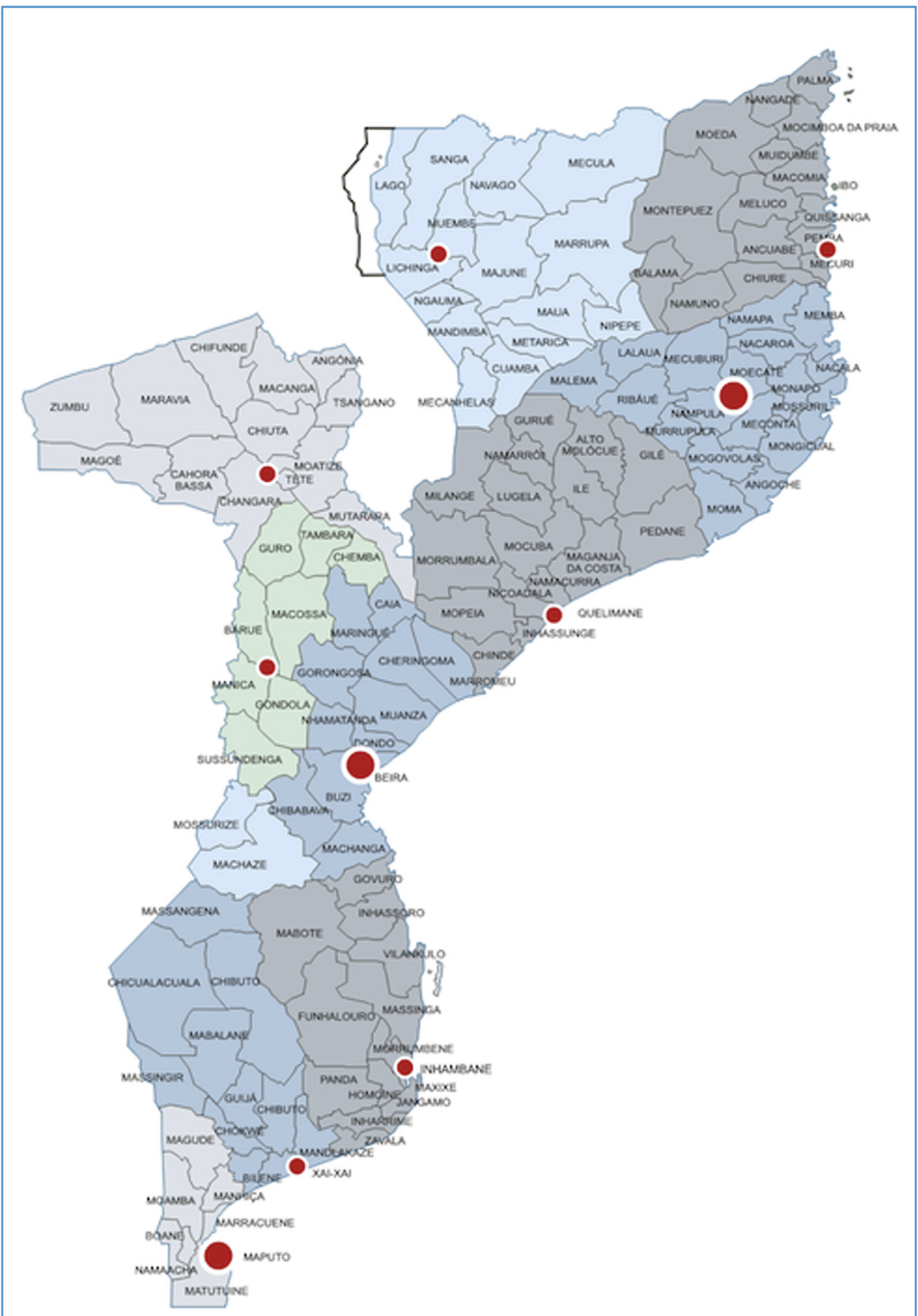

Figure 1. Map of Mozambique with 129 districts identified. The small red dots are the provincial capitals, and the large red dots identify the main cities with neurosurgical care.

Niassa province (55.3\% in Nampula province). Overall low levels of education in pregnant women contribute to these low coverage rates $(\mathrm{I} 7, \mathrm{I} 8)$.
The Nampula Central Hospital is the quaternary reference hospital for the country's northern region, covering more than one third of the country's population $(17,35)$. There is only I Mozambican 


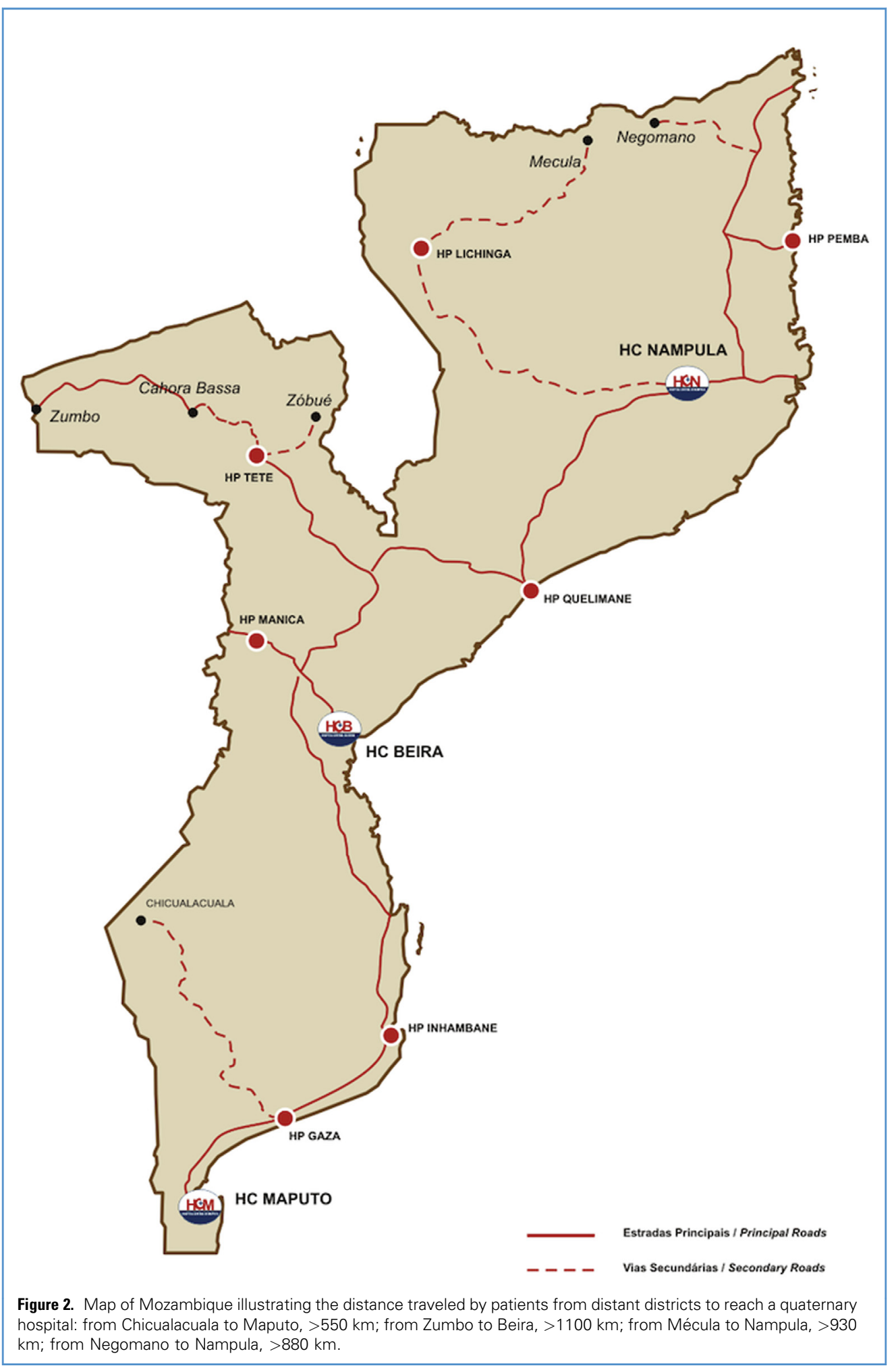

neurosurgeon dedicated to serving this large segment of the population. The Nampula Central Hospital has 540 beds (196 pediatric), 24 intensive care unit beds (I2 pediatric), and 6 operating rooms.
Neurosurgery is integrated into general surgery wards, with 26 adult and 4 pediatric beds dedicated to the service, but there is often a need for additional beds, particularly for children. The service 
annually has 600 admissions, 500 major surgical procedures and Iooo minor surgical procedures, and 2600 outpatient visits.

\section{MATERIALS AND METHODS}

Using retrospective clinical care data from a previous study (27), the domestic origin of patients with hydrocephalus who underwent surgical treatment (VPS) was reviewed, and rates of loss to follow-up were determined. The follow-up loss is proportional to the distance of the patients to the referral hospital. Based on these data, we tried to understand what factors could be at the root of this problem with referral and follow-up.

\section{DISCUSSION}

The literature about hydrocephalus in Africa starts in 1963 with an article by Clifford (4). In I984, an important series on hydrocephalus in Africa was published by Peacock and Currer (22). Of hydrocephalus articles indexed on PubMed, $<\mathrm{I} \%$ come from Africa. The care of hydrocephalus in sub-Saharan Africa is hampered by economic constraints (poverty), difficulties for patients and families concerning transportation and access to adequate care, and cultural beliefs and misunderstandings related to hydrocephalus (I4, 35). No epidemiologic data on hydrocephalus in Mozambique are available. It is believed that developing countries such as Mozambique have an incidence of congenital hydrocephalus equivalent to or greater than developed countries and that postinfectious acquired hydrocephalus occurs at even higher rates $(34,35)$. The increased prevalence in Africa is believed to be due to an increase in birth rate and an increase in occurrence of congenital abnormalities associated with increased rates of neonatal infections, substandard diagnosis and treatment of meningitis, poor coverage of human immunodeficiency virus, pneumococcal immunizations, and folate deficiency (Io, 23, 34). Low socioeconomic status is a risk for all nongenetic (acquired) defects, including hydrocephalus (3I). Nongenetic structural defects can occur for several reasons. Hydrocephalus is strongly associated with myelomeningocele, and this defect is caused by a deficiency of folic acid in the maternal diet (I5, 2I). Multivitamin supplements during pregnancy have been shown to reduce the risk of hydrocephalus (II, I5). Low maternal age has been associated with a higher risk of hydrocephalus, probably because younger mothers are less likely to receive prenatal screening (25). Maternal age at first birth is low in many developing countries; in Mozambique, most primigravid women are between 20 and 24 years old ( 17 ).

The diagnosis of hydrocephalus is underestimated in northern Mozambique, likely related to health personnel not being properly trained to diagnose hydrocephalus at delivery and neonatal care. Moreover, only half of pregnant women in northern Mozambique access neonatal care $(50.4 \%)$ ( 17,18$)$, which further reduces the ability to diagnose neonatal hydrocephalus (50\%). The incidence of infantile hydrocephalus in the northern region was conservatively estimated to be 1700 cases/year, of which only $15 \%$ are likely referred. More than half of the cases referred had classic and advanced hydrocephalus stigmata, such as macrocephaly, intracranial hypertension, and neurodevelopmental delay (27). Most pediatric patients referred to Nampula Central Hospital arrived with advanced cases, and severe hydrocephalus stigmata were common- $>90 \%$ had a cranial perimeter above the 9oth percentile and taut fontanel, and $>50 \%$ had some degree of psychomotor development impairment with $15 \%$ with significant developmental delays.

These late sequelae often can be avoided by early diagnosis and timely treatment. There is a crucial need to train health personnel from primary and secondary health care levels to promote prevention, ensure early diagnosis, and ensure timely referral. Measures to improve assistance at these health care levels include the following:

I. Prevent neural tube defects secondary to lack of folates/folic acid (one of the common causes of infant hydrocephalus in Africa) by providing folic acid during pregnancy (35).

2. Prevent neonatal meningitis (another common cause of infant hydrocephalus in Africa) by improving delivery and neonatal conditions (35) with appropriate assistance during pregnancy and delivery, early diagnosis, and appropriate orientation.

3. Provide community education and sensitization to address existing misconceptions about hydrocephalus.

4. Improve the training of health care professionals in prevention, early diagnosis, and appropriate prompt referral of new cases and cases with posttreatment complications.

5. Improve diagnostic capacity by introducing transfontanellar ultrasound, which is preferred for settings such as Mozambique because of its relative simplicity and lower cost compared with magnetic resonance imaging and computed tomography.

Mozambique went through almost 3 decades of war and internal conflict, which led to a critical loss of facilities and human resources, including qualified health professionals. The country finally is beginning to take the first steps to overcome the socioeconomic and cultural difficulties of the recent past, and as such rapid systemic changes are difficult. However, significant progress has been made in the medical field.

The training of health professionals (particularly individuals working in primary and secondary health care) on the causes, prevention, and diagnosis of hydrocephalus should be a focal point for improved patient outcomes in Mozambique. These health professionals are at the frontlines of the national health care system, see high volumes of patients, and can effectively:

Educate and sensitize the community about the importance of prenatal care and facility deliveries.

- Provide iron and folic acid supplementation during pregnancy.

- Attend deliveries, provide sterile conditions for childbirth, and make an early diagnosis of congenital and neonatal hydrocephalus, with timely referrals to a neurosurgeon.

- After training, perform transfontanellar ultrasound in health facilities to aid the diagnosis of hydrocephalus.

During medical education, neurosurgical topics are included in general surgery courses. This training for general practitioners 
should include not only hydrocephalus but also brain injury, clinical manifestations of brain tumors, intracranial hemorrhage, and spinal pathology (degenerative, traumatic, and oncologic). This educational base would provide general physicians the tools needed to diagnose and manage and refer appropriately cases for neurosurgical care. Because much clinical care in Mozambique is provided by general practitioners, it is important to include these subjects in their education as well. These health professionals, equipped with better theoretical and practical knowledge, could transfer patients directly to neurosurgical centers, avoiding wasted time and unnecessary expenses associated with the referral system currently in use in Mozambique.

Cerebrospinal fluid shunt systems as well as neurosurgeons able to insert them are unavailable for most children, and, when available, most patients still do not have access to VPS (35). A VPS is available at quaternary level of care, and the National Health System in Mozambique currently offers the Chhabra Surgywear valve (Surgiwear company, Shahjahanpur, India) system. Even with higher rates of major complications, VPS remains the primary treatment option in the orientation of hydrocephalus. Worldwide, the range of complication rates is $1 \%-50 \%$ in the 2 years after placement $(6,7,10,32,35,38)$, including VPS system failures and infections (I0, I3, I9, 32, 35). Chhabra Surgywear VPS systems (now routinely used in Mozambique) have similar complication rates to systems used in Western countries, without statistically significant differences in complications, as reported in a study in Uganda (32).

In sub-Saharan Africa, reported complications are between $7 \%$ and $69 \%$, related to mechanical causes $(\mathrm{II} \%-54 \%)$ and infection $(7 \%-69 \%)(2,19,22,24,26,29,30,34)$. Even when VPS placement is possible, it is more dangerous in Africa because of the complications (infection and shunt malfunction) (32). Patient follow-up after the procedure is a major challenge, with almost half of treated patients being lost to follow up, often related to the long distances from patients' homes to health facilities (27). Economic difficulties related to extreme poverty, difficult access, and long distances constrain the appropriate follow-up of these children and contribute to the low rates of patient retention.

Numerous children alternatively may benefit from endoscopic third ventriculostomy, which is a treatment option without heterologous material; with a long-term lower rate of associated complications $(9$, I4 , 29, 33); and with a follow-up that we believe can be less frequent, reducing the socioeconomic stressors on the families of these patients $(36,37)$.

It is impossible to improve health facility infrastructure and access rapidly in the short-term in a large developing country such as Mozambique, but major efforts have been undertaken by government in the last decade to improve the situation. Alternative measures to provide neurosurgical care to the population, provide new treatment options, and avoid follow-up losses are key to reducing the burden of neurosurgical problems at the quaternary health care level. Some measures to improve the situation in the short-term to mid-term include the following:

I. Avoid VPS infectious complications by implementing standard protocols covering the preoperative, surgical, and postoperative periods, as reported by Choux et al. (3).
2. Introduce alternative treatment options, such as endoscopic third ventriculostomy with or without choroid plexus cauterization, which have lower costs for the health system in the short-term and mid-term, better results for the patient, and lower socioeconomic impact on the families of patients. The average cost of this equipment is around $\$ 50,000$ (I6), with investment recovered after about 500 procedures, without including shorter periods of hospitalization, reduced need for hospital visits for follow-up, fewer complications, and its strong socioeconomic impact on families $(36,37)$, as reported on endoscopic third ventriculostomy procedures.

In the mid-term to long-term, the more complex and timeconsuming step would be to train more neurosurgeons to be placed in provincial health facilities with sufficient infrastructure for them to provide high-quality neurosurgical care. Neurosurgical training takes $5^{-6}$ years of postgraduate medical education, and the infrastructure and equipment needed are expensive. However, the implementation of a policy focused on this issue can help achieve this goal in the mid-term to long-term. Cooperative protocols with neurosurgery departments in institutions with experience in hydrocephalus and other neurosurgical areas could be a short-term to mid-term option to reduce the impact of this shortage. It could also create teaching conditions for (I) postgraduate training for Mozambican neurosurgeons in the most current and advanced techniques in the management of hydrocephalus; (2) updating general practitioners and medical technicians who provide services at the primary, secondary, and tertiary levels; and (3) assisting in pregraduate training of general physicians and medical technicians.

\section{CONCLUSIONS}

To improve the quality of care of patients with hydrocephalus in a country with a social, economic, and cultural context such as Mozambique is a challenge that goes far beyond the biomedical considerations of neurosurgical treatment. Hydrocephalus in subSaharan Africa is a serious health problem. Although research is increasingly focusing on this issue, there are still few data on its incidence, prevalence, and causes. In northern Mozambique, there is an urgent need for strategies to address this treatable medical condition, which has devastating consequences when untreated. A new health care approach to hydrocephalus in Mozambique is of utmost importance to improve performance in terms of prevention, access, quality, and retention in care. The issues addressed in this article are likely applicable to many developing countries with conditions similar to northern Mozambique, and we hope this article can serve as the basis for a more exhaustive evaluation of strategies to improve hydrocephalus care in Mozambique.

\section{ACKNOWLEDGMENTS}

We thank Luís Cardoso for drawing the maps and W. Chris Buck and Joaquim Salvador for language editing and criticism of the article. 


\section{REFERENCES}

I. Aschoff A, Kremer P, Hashemi B, Kunze S: The scientific history of hydrocephalus and its treatment. Neurosurg Rev 22:67-93; discussion 94-95, I999.

2. Ba MC, Kpelao ES, Thioub M, Kouara M, Thiam AB, Ndoye N, Sakho Y, Badiane SB: Post meningitis hydrocephalus in the infants in Dakar [in French]. Afr J Neurol Sci 3I:8-I5, 2012.

3. Choux M, Genitori L, Lang D, Lena G: Shunt implantation: reducing the incidence of shunt infection. J Neurosurg 77:875-88o, I992.

4. Clifford P: Infantile hydrocephalus. Some clinical and pathological aspects: I. clinical aspects. East Afr Med J 40:534-544, 1963.

5. Del Bigio MR: Epidemiology and direct economic impact of hydrocephalus: a community based study. Can J Neurol Sci 25:I23-I26, I998.

6. Drake J, Kestle JR, Tuli S: CSF shunts 50 years onpast, present and future. Childs Nerv Syst I6: 800-804, 2000.

7. Drake JM, Kestle JR, Milner R, Cinalli G, Boop F, Piatt J Jr, Haines S, Schiff SJ, Cochrane DD, Steinbok P, MacNeil N: Randomized trial of cerebrospinal fluid shunt valve design in pediatric hydrocephalus. Neurosurgery 43:294-303; discussion 303-305, I998.

8. Frim DM, Scott RM, Madsen JR: Surgical management of neonatal hydrocephalus. Neurosurg Clin N Am 9:105-IIo, I998.

9. Garton HJ, Kestle JR, Cochrane DD, Steinbok P: A cost-effectiveness analysis of endoscopic third ventriculostomy. Neurosurgery 51:69-77; discussion $77-78,2002$.

Io. Gathura E, Poenaru D, Bransford R, Albright AL: Outcomes of ventriculoperitoneal shunt insertion in sub-Saharan Africa. J Neurosurg Pediatr 6: 329-335, 2010

II. Goh YI, Bollano E, Einarson TR, Koren G: Prenatal multivitamin supplementation and rates of congenital anomalies: a meta-analysis. J Obstet Gynaecol Can 28:68o-689, 2006.

I2. Kestle J, Garton HJ, Drake J: Treatment of hydrocephalus with shunts. In: Albright $\mathrm{AL}$, Pollack IF, Adelson PD, eds. Principles and Practice of Pediatric Neurosurgery. New York: Thieme; I999:75-90.

13. Komolafe EO, Adeolu AA, Komolafe MA: Treatment of cerebrospinal fluid shunting complications in a Nigerian neurosurgery programme. Case illustrations and review. Pediatr Neurosurg 44: 36-42, 2008.

I4. Kulkarni AV, Warf BC, Drake JM, Mallucci CL, Sgouros S, Constantini S: Surgery for hydrocephalus in sub-Saharan Africa versus developed nations: a risk-adjusted comparison of outcome. Childs Nerv Syst 26:I7II-I717, 2010

15. Margaron FC, Poenaru D, Bransford R, Albright AL: Timing of ventriculoperitoneal shunt insertion following spina bifida closure in Kenya. Childs Nerv Syst 26:1523-I528, 2010.

I6. Direcção de Assistência Médica e Medicamentosa Unpublished annual reports. Hospital Central de Nampula Direcção Provincial de Saúde - Departamento de Assistência Médica e Medicamentosa. Nampula; 2012.

17. Moçambique I. Inquérito Demográfico e de Saúde; 20II. Available at: http://dhsprogram.com/ pubs/pdf/FR266/FR266.pdf. Accessed July 8, 2015.

I8. Moçambique Instituto Nacional de Estatística. 20II. Available at: http://www.ine.gov.mz/ estatisticas/estatisticas-demograficas-e-

indicadores-sociais/projeccoes-da-populacao/ indicadores-demograficos-mocambique-20072040.xlsx/view. Accessed July 8, 2015.

19. Mwachaka PM, Obonyo NG, Mutiso BK Ranketi S, Mwang'ombe N: Ventriculoperitoneal shunt complications: a three-year retrospective study in a Kenyan national teaching and referral hospital. Pediatr Neurosurg 46:I-5, 2010.

20. Oi S: Hydrocephalus research update-controversies in definition and classification of hydrocephalus. Neurol Med Chir (Tokyo) 50:859-869, 2010.

2I. Partington MD: Congenital hydrocephalus. Neurosurg Clin N Am I2:737-742, 2001.

22. Peacock WJ, Currer TH: Hydrocephalus in childhood. A study of 440 cases. S Afr Med J 66: 323-324, I984.

23. Piquer J, Qureshi MM, Young PH: Impact of mobile endoscopy on neurosurgical development in East Africa. World Neurosurg 73:280-284, 2010.

24. Reddy GK, Bollam P, Caldito G: Ventriculoperitoneal shunt surgery and the risk of shunt infection in patients with hydrocephalus: longterm single institution experience. World Neurosurg 78:I55-I63, 2012.

25. Reefhuis J, Honein MA: Maternal age and nonchromosomal birth defects, Atlanta-I968-2000: teenager or thirty-something, who is at risk? Birth Defects Res A Clin Mol Teratol 70:572-579, 2004.

26. Richards HK, Seeley HM, Pickard JD: Efficacy of antibiotic-impregnated shunt catheters in reducing shunt infection: data from the United Kingdom Shunt Registry. J Neurosurg Pediatr 4: 389-393, 2009

27. Salvador SF, Henriques JC, Munguambe M, Vaz R, Barros H: Hydrocephalus in children less than I year of age in northern Mozambique. Surg Neurol Int 5:175, 20I4.
28. Sandberg DI: Endoscopic management of hydrocephalus in pediatric patients: a review of indications, techniques, and outcomes. J Child Neurol 23:550-56o, 2008

29. Tambo FF, Djientcheu V, Chiabi A, Mbarnjuk SA, Walburga YJ, Mbonda E, Sosso MA: Our experience in the management of infantile hydrocephalus: a study on thirty-five regrouped cases in Yaounde, Cameroon. Afr J Paediatr Surg 8: I99-202, 2011.

3o. Vinchon M, Rekate H, Kulkarni AV: Pediatric hydrocephalus outcomes: a review. Fluids Barriers CNS 9:I8, 2012.

3I. Vrijheid M, Dolk H, Stone D, Abramsky L, Alberman E, Scott JE: Socioeconomic inequalities in risk of congenital anomaly. Arch Dis Child 82: 349-352, 2000

32. Warf B: Comparison of I-year outcomes for the Chhabra and Codman-Hakim Micro Precision shunts in Uganda: a prospective study in 195 children. J Neurosurg I02:358-362, 2005.

33. Warf BC: Hydrocephalus associated with neural tube defects: characteristics, management, and outcome in sub-Saharan Africa. Childs Nerv Syst 27:I589-I594, 20II.

34. Warf BC: Hydrocephalus in Uganda: the predominance of infectious origin and primary management with endoscopic third ventriculostomy. J Neurosurg IO2 (I Suppl):I-I5, 2005.

35. Warf BC: Pediatric hydrocephalus in East Africa: prevalence, causes, treatments, and strategies for the future. World Neurosurg 73:296-300, 2010.

36. Warf BC, Alkire BC, Bhai S, Hughes C, Schiff SJ, Vincent JR, Meara JG: Costs and benefits of neurosurgical intervention for infant hydrocephalus in sub-Saharan Africa. J Neurosurg Pediatr 8: 509-52I, 20 II.

37. Warf BC, Bhai S, Kulkarni AV, Mugamba J: Shun survival after failed endoscopic treatment of hydrocephalus. J Neurosurg Pediatr Io:463-470, 2012.

38. Weprin BE, Swift DM: Complications of ventricular shunt. Tech Neurosurg 7:224-242, 2002.

Conflict of interest statement: The authors declare that the article content was composed in the absence of any commercial or financial relationships that could be construed as a potential conflict of interest.

Received 8 December 2014; accepted 31 March 2015 Citation: World Neurosurg. (2015) 84, 3:671-676. http://dx.doi.org/10.1016/j.wneu.2015.03.064 Journal homepage: www.WORLDNEUROSURGERY.org

\section{Available online: www.sciencedirect.com}

1878-8750/\$ - see front matter (c) 2015 Elsevier Inc. All rights reserved. 